\title{
Welcome to the ninth volume of pain management
}

\author{
Alice Bough*,1 \\ ${ }^{1}$ Future Science Group, Unitec House, 2 Albert Place, London, N31QB, UK \\ *Author for correspondence: a.bough@futuremedicine.com
}

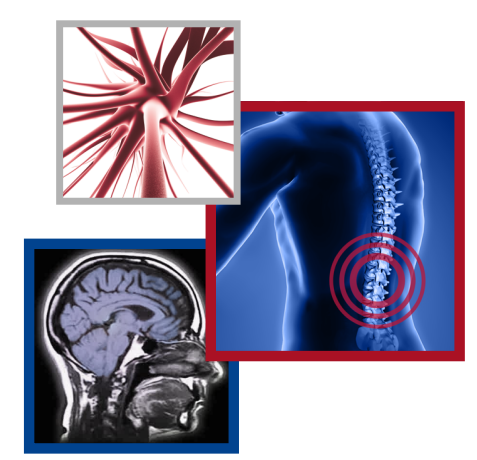

First draft submitted: 10 October 2018; Accepted for publication: 10 October 2018; Published online: 19 December 2018

Keywords: fibromyalgia • opioids • pain management • pediatric pain • research $\bullet$ social media

To all our readers, we are delighted to welcome you to the ninth volume of Pain Management and are pleased to introduce you to the first issue of 2019.

The 2018 was another exciting year for the journal with the continued publication of timely, high-quality manuscripts. We are proud to present some of our content highlights within this article.

\section{Content highlights of 2018}

At the time of writing (October 2018), our most read article of the last year was a review entitled 'Pharmacokinetic properties of intranasal and injectable formulations of naloxone for community use: a systematic review'. This paper was authored by researchers from University of Cincinnati College of Medicine (OH, USA) and Wayne State University School of Medicine (MI, USA) [1].

Our second most read article was another review on a similar subject entitled 'Prescribing naloxone for opioid overdose intervention'. Both papers discussed the importance of naloxone in the emergency treatment of opioid overdose [1,2]. Both of these papers must be commended as they achieved the highest Altmetric scores of all articles in Pain Management in 2018 (Table 1).

Our most read editorial article was 'Prioritizing pediatric chronic pain and comprehensive pain treatment in the context of the opioid epidemic'. The authors highlighted the problems associated with pediatric chronic pain and explained that a lack of education about its management is perpetuating the need for treatment of opioid abuse [3].

We always try to balance the content of Pain Management to cover a variety of pharmacological and nonpharmacological techniques. Indeed, another of our most read editorials was an article entitled 'Benefits of Tai Chi for fibromyalgia'. The authors described the struggles for patients living with fibromyalgia and explained the benefits Tai Chi can have on their health [5].

\section{Altmetric scores}

As we continue our successful partnership with Altmetric, special mention must be given to the papers included in Table 1. They have achieved the highest Altmetric scores in Pain Management in 2018.

\section{Readership demographics}

It is great to see that in 2018, our journal is being read throughout the world, with the highest number of readers being from North America (56\%) and Europe (21\%) (Figure 1). In terms of individual countries, the highest number of readers originated from the USA (52\%). It is encouraging to see an increase in the number of readers from Africa. We look forward to continuing the circulation of our journal content to an increasingly global audience in the upcoming year.

\section{Authorship demographics}

It is interesting to see where in the world the content of Pain Management comes from. In 2018, authors from the USA submitted $46 \%$ of all content while the European country with the most submissions was the UK (16\%) (Figure 2). Brazil, Canada and Spain each contributed an equal number of articles to Pain Management (8\%). We continue to welcome manuscript submissions from across the world and encourage unsolicited article proposals.

Future $\because$ Medicine 


\section{Readership Demographics}

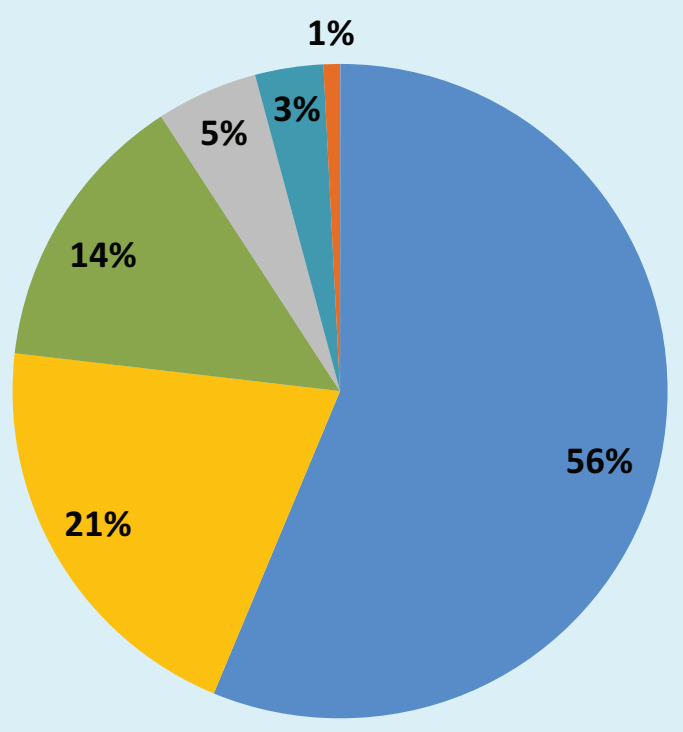

North America

Europe

Asia

Oceania

South America

Africa

Figure 1. Proportion of readership demographics for Pain Management in 2018.

\section{Authorship Demographics}

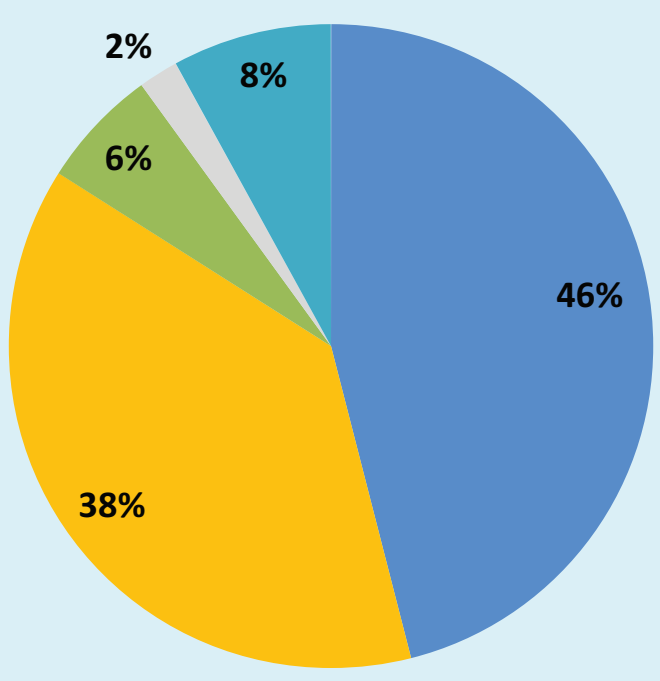

North America

Europe

Asia

Oceania

South America

Figure 2. Proportion of authorship demographics for Pain Management in 2018. 


\begin{tabular}{|c|c|c|c|c|}
\hline Title & Article type & Authors & $\begin{array}{l}\text { Altmetric } \\
\text { score }\end{array}$ & Ref. \\
\hline $\begin{array}{l}\text { Pharmacokinetic properties of intranasal and injectable formulations of } \\
\text { naloxone for community use: a systematic review }\end{array}$ & Review & Ryan SA \& Dunne RB & 329 & [1] \\
\hline Prescribing naloxone for opioid overdose intervention & Review & Dunne RB & 310 & [2] \\
\hline $\begin{array}{l}\text { Effect of virtual reality headset for pediatric fear and pain distraction during } \\
\text { immunization }\end{array}$ & Research Article & $\begin{array}{l}\text { Chad R, Emaan S \& Jillian } \\
\text { O }\end{array}$ & 22 & [4] \\
\hline $\begin{array}{l}\text { Prioritizing pediatric chronic pain and comprehensive pain treatment in the } \\
\text { context of the opioid epidemic }\end{array}$ & Editorial & Martin SR \& Zeltzer LK & 20 & [3] \\
\hline
\end{tabular}

\section{Social media}

Pain Management continues to be active across social media including on our Twitter @fsgpmt [6], on which we have over 2400 followers and being associated with the LinkedIn group for the Future Science Group website NeuroCentral [7]. We have thoroughly enjoyed engaging with pain management professionals across the field this year. We encourage our readers to connect with us via social media as we continue into 2019.

\section{Conclusion}

As always, we welcome all feedback from the community regarding the direction our journal is taking and any suggestions for topics you wish to see covered in Pain Management. As mentioned previously, we accept unsolicited articles of all forms, original research articles, reviews and opinion articles. Please get in contact if you are interested in submitting. In particular we are looking for submissions surrounding key areas such as:

- Physiology and mechanisms of pain;

- Transition from acute to chronic pain;

- Therapeutic options;

- New concepts and breakthroughs in pain control;

- Interventional procedures;

- Nonpharmacologic approaches;

- Acute and postoperative pain control;

- Pain management in oncology;

- Special pain syndromes;

- Palliative care;

- Pediatric and aging health;

- Pharmacology and addiction/abuse of pain medication;

- Adverse events and drug safety;

- Pharmacoeconomics, outcomes research and quality of life.

We would like to take this opportunity to thank all of our valued Editorial Board members, readers and contributors for their continued support. We greatly look forward to collaborating with you all over the coming year.

Financial \& competing interests disclosure

A Bough is an employee of Future Science Ltd, publisher of Pain Management. The author has no other relevant affiliations or financial involvement with any organization or entity with a financial interest in or financial conflict with the subject matter or materials discussed in the manuscript apart from those disclosed.

No writing assistance was utilized in the production of this manuscript.

\section{References}

1. Ryan SA, Dunne RB. Pharmacokinetic properties of intranasal and injectable formulations of naloxone for community use: a systematic review. Pain Manag. 8(3), 231-245 (2018).

2. Dunne RB. Prescribing naloxone for opioid overdose intervention. Pain Manag. 8(3), 197-208 (2018).

3. Martin SA, Zeltzer LK. Prioritizing pediatric chronic pain and comprehensive pain treatment in the context of the opioid epidemic. Pain Manag. 8(2), 67-70 (2018). 
4. Chad R, Emaan S, Jillian O. Effect of virtual reality headset for pediatric fear and pain distraction during immunization. Pain Manag. 8(3), 175-179 (2018).

5. Sawynok J. Benefits of Tai Chi for fibromyalgia. Pain Manag. 8(4), 247-250 (2018).

6. Pain Management Journal. Twitter. https://twitter.com/fsgpmt

7. Future Science Group Neurology. LinkedIn. https://www.linkedin.com/groups/8204606/profile 